NASA

Technical Memorandum 106080

AIAA-93-2149
Army Research Laboratory

Memorandum Report ARL-MR-71

\title{
Low-Noise, High-Strength, Spiral-Bevel Gears for Helicopter Transmissions
}

David G. Lewicki and Robert F. Handschuh

Vehicle Propulsion Directorate

U.S. Army Research Laboratory

Lewis Research Center

Cleveland, Ohio

Zachary S. Henry

Bell Helicopter Textron, Inc.

Fort Worth, Texas

and

Faydor L. Litvin

University of Illinois at Chicago

Chicago, Illinois

Prepared for the

29th Joint Propulsion Conference and Exhibit

cosponsored by the AIAA, SAE, ASME, and ASEE

Monterey, California, June 28-30, 1993 


\title{
LOW-NOISE, HIGH-STRENGTH, SPIRAL-BEVEL GEARS FOR HELICOPTER TRANSMISSIONS
}

\author{
David G. Lewicki and Robert F. Handschuh \\ Vehicle Propulsion Directorate \\ U.S. Army Research Laboratory \\ Lewis Research Center \\ Cleveland, Ohio 44135 \\ Zachary S. Henry \\ Bell Helicopter Textron, Inc. \\ Fort Worth, Texas 76101 \\ and \\ Faydor L. Litvin \\ University of Illinois at Chicago \\ Chicago, Ilinois 60680
}

\begin{abstract}
$\underline{\text { Abstract }}$
Improvements in spiral-bevel gear design were investigated to support the Army/NASA Advanced Rotorcraft Transmission program. Program objectives were to reduce weight by 25 percent, reduce noise by $10 \mathrm{~dB}$, and increase life to $5000 \mathrm{hr}$ mean-time-betweenremoval. To help meet these goals, advanced-design spiral-bevel gears were tested in an OH-58D helicopter transmission using the NASA 500-hp Helicopter Transmission Test Stand. Three different gear designs tested included: (1) the current design of the $\mathrm{OH}-58 \mathrm{D}$ transmission except gear material X-53 instead of AISI 9310, (2) a higher-strength design the same as the current but with a full fillet radius to reduce gear tooth bending stress (and thus, weight), and (3) a lower-noise design the same as the high-strength but with modified tooth geometry to reduce transmission error and noise. Noise, vibration, and tooth strain tests were performed and significant gear stress and noise reductions were achieved.
\end{abstract}

\section{$\underline{\text { Introduction }}$}

Spiral-bevel gears are used extensively in rotorcraft applications to transfer power and motion through nonparallel shafts. In helicopter applications, spiral-bevel gears are used in main-rotor and tail-rotor gearboxes to drive the rotors. In tilt-rotor applications, they are used in interconnecting drive systems to provide mechanical connection between two prop-rotors in case one engine becomes inoperable. Even though spiral-bevel gears have had considerable success in these applications, they are a main source of vibration in gearboxes, and thus, a main source of noise in cabin interiors (Lewicki and Coy, 1987; Mitchell, et al., 1986). In addition, higher strength and lower weight are required to meet the needs of future aircraft (Vialle, 1991). An effort to improve the technology of components such as spiral-bevel gears has been the Advanced Rotorcraft Transmission (ART) program.

The ART program was an Army-funded, Army/ NASA program to develop and demonstrate lightweight, quiet, durable drive systems for next generation rotorcraft (Bill, 1990). The ART program goals were to reduce drive system weight by 25 percent, reduce noise by $10 \mathrm{~dB}$, and increase life to $5000 \mathrm{hr}$ mean-timebetween-removal by using new ideas in gear configuration, transmission concepts, and airframe-drive train integration. The success of the ART design configurations in meeting the program goals depended on the successful incorporation of certain critical, advanced technologies into the preliminary designs. The U.S. Army Vehicle Propulsion Directorate, NASA Lewis Research Center, Bell Helicopter Textron (one ART contractor participant), the University of Illinois at Chicago (subcontractor to Bell Helicopter Textron), and the Gleason Works (subcontractor to Bell Helicopter Textron) were involved in a joint project to improve spiral-bevel gears. The project goals were to reduce bevel gear noise and increase strength through changes in gear tooth surface geometry, and tooth fillet and root designs (Henry, 1991; Henry, 1992).

Various investigators have studied spiral-bevel gears and their influence on vibration and noise (Litvin and Zhang, 1991a; Gosselin, 1991; Fong and Tsay, 1992). Most agree that transmission error, defined as the difference in relative motion of an output gear with respect to the input pinion, is the major contributor to undesirable vibration and noise. A common practice is to modify spiral-bevel gear surface topology to permit operation in a misaligned mode. Over compensation for this type of operation, however, leads to large 
transmission error and higher noise and vibration levels. In the Army/NASA/Bell joint project, gears with tooth surfaces designed for reduced transmission errors using methods of Litvin and Zhang (1991a) were manufactured and tested. The teeth were designed to exhibit a parabolic function of transmission error at a controlled low level ( 8 to $10 \mathrm{arc} \mathrm{sec}$ ). The low level of transmission error reduces the vibration and noise caused by the mesh. The new tooth geometries for this design were achieved through slight modification of the machine tool settings used in the manufacturing process. The design analyses addressed tooth generation, tooth contact analysis, transmission error prediction, and effects of misalignment (Litvin and Zhang, 1991a; Litvin et al., 1991b; Litvin et al., 1991c).

Also as part of the Army/NASA/Bell project, gears with tooth fillet and root modifications to increase strength were manufactured and tested. By increasing these radii, reduced stresses were achieved, and thus, increased strength. Tooth fillet radii larger than those on current gears were made possible by recent advances in spiral-bevel gear grinding technology (Scott, 1991). Advanced gear grinding was achieved through redesign of a current gear grinder and the addition of computer numerical control.

The objective of this report is to describe the results of the experiments to evaluate advanced spiralbevel gear designs. The work was part of a joint Army/ NASA/Bell project in support of the ART program. Experimental tests were performed on the $\mathrm{OH}-58 \mathrm{D}$ helicopter main-rotor transmission in the NASA 500-hp Helicopter Transmission Test Stand. The baseline OH-58D spiral-bevel gear design, a low-noise design, and a high-strength design were tested. Results of noise, vibration, and tooth strain tests are presented.

\section{Apparatus}

\section{$\underline{\mathrm{OH}-58 \mathrm{D} \text { Main-Rotor Transmission }}$}

The $\mathrm{OH}-58$ Kiowa is an Army single-engine, light, observation helicopter. The $\mathrm{OH}-58 \mathrm{D}$ is an advanced version developed under the Army Helicopter Improvement Program (AHIP). The OH-58D main-rotor transmission is shown in Fig. 1. It is currently rated at maximum continuous power of $346 \mathrm{~kW}$ ( $464 \mathrm{hp}$ ) at $6016 \mathrm{rpm}$ input speed, with the capability of $10 \mathrm{sec}$ torque transients to $485 \mathrm{~kW}$ ( $650 \mathrm{hp}$ ), occurring once per hour, maximum. The main-rotor transmission is a two-stage reduction gearbox with an overall reduction ratio of 15.23:1. The first stage is a spiral-bevel gear set with a 19-tooth pinion that meshes with a 62 -tooth gear. Triplex ball bearings and one roller bearing support the bevel-pinion shaft. Duplex ball bearings and one roller bearing support the bevel-gear shaft. Both pinion and gear are straddle mounted.

A planetary mesh provides the second reduction stage. The bevel-gear shaft is splined to a sun gear shaft. The 27-tooth sun gear meshes with four 35 -tooth planet gears, each supported with cylindrical roller bearings. The planet gears mesh with a 99-tooth fixed ring gear splined to the transmission housing. Power is taken out through the planet carrier splined to the output mast shaft. The output shaft is supported on top by a splitinner-race ball bearing and on bottom by a roller bearing. The 62-tooth bevel gear also drives a 27-tooth accessory gear. The accessory gear runs an oil pump, which supplies lubrication through jets and passageways located in the transmission housing.

\section{Spiral-Bevel Test Gears}

Three different spiral-bevel gear designs were tested. The first was the baseline $\mathrm{OH}-58 \mathrm{D}$ design. Table I lists a variety of parameters for this baseline set. The reduction ratio of the bevel set is 3.26:1. The gears were made using standard aerospace practices where the surfaces were carburized and ground. The material used for all test gears was X-53 (AMS 6308) rather than the conventional AISI 9310 (AMS 6265).

The second spiral-bevel design tested was an increased strength design. The configuration was identical to the baseline except that the tooth fillet radius of the pinion was increased from 0.51 to $1.02 \mathrm{~mm}(0.020$ to $0.040 \mathrm{in}$.), and the gear was made full fillet (Fig. 2). The high-strength design was made possible by recent advances in gear grinding technology (Scott, 1991).

The third spiral-bevel design tested was a low-noise design. The low-noise design was identical to the increased-strength design except the pinion was slightly altered to reduce transmission error. The gear member was unchanged. The low-noise design was based on the idea of local synthesis that provided at the mean contact point the following conditions of meshing and contact (Litvin and Zhang, 1991a): (1) the required gear ratio and its derivative, (2) the desired direction of the tangent to the contact path, and (3) the desired major axis of the instantaneous contact ellipse. The local synthesis was complemented with a tooth contact analysis. Using this approach, the machine tool settings for reduced noise were determined. As with the highstrength design, precise control of the manufactured tooth surfaces were made possible by advances in the final grinding operation machine tool (Scott, 1991). Figure 3 gives a topological comparison between a lownoise and baseline spiral-bevel pinion tooth. The dotted lines are the baseline tooth datum and the solid lines are 
the measured difference in topology of a low-noise gear compared to the baseline. Solid lines above the dotted plain indicate an addition of material and lines below the plain indicate a removal. The effect of the topological change in the low-noise design was a reduction in overall crowning of the tooth, leading to an increase in contact ratio and reduced transmission error.

\section{NASA 500-HP Helicopter Transmission Test Stand}

The OH-58D transmission was tested in the NASA Lewis 500-hp helicopter transmission test stand (Fig. 4). The test stand operates on the closed-loop or torqueregenerative principle. Mechanical power recirculates through a closed loop of gears and shafting, part of which is the test transmission. The output of the test transmission attaches to the bevel gearbox. The output shaft of the bevel gearbox passes through a hollow shaft in the closing-end gearbox and connects to the differential gearbox. The output of the differential attaches to the hollow shaft in the closing-end gearbox. The output of the closing-end gearbox connects to the speed decreaser gearbox. The output of the speed decreaser gearbox attaches to the input of the test transmission, thereby closing the loop.

A $149-\mathrm{kW}\left(200-\mathrm{hp}_{\mathrm{p}}\right)$ variable-speed direct-current (dc) motor powers the test stand and controls the speed. The motor output attaches to the closing-end gearbox. The motor replenishes losses due to friction since power recirculates around the loop. An 11-kW (15-hp) dc motor provides the torque in the closed loop. The motor drives a magnetic particle clutch. The clutch output does not turn but exerts a torque. This torque is transferred through a speed reducer gearbox and a chain drive to a large sprocket on the differential gearbox. The torque on the sprocket applies torque in the closed loop by displacing the gear attached to the output shaft of the bevel gearbox with respect to the gear connected to the input shaft of the closing-end gearbox. This is done within the differential gearbox through use of a compound planetary system where the planet carrier attaches to the sprocket housing. The magnitude of torque in the loop is adjusted by changing the electric field strength of the magnetic particle clutch.

A mast shaft loading system in the test stand simulates rotor loads imposed on the $\mathrm{OH}-58 \mathrm{D}$ transmission output mast shaft. The $\mathrm{OH}-58 \mathrm{D}$ transmission output mast shaft connects to a loading yoke. Two vertical load cylinders connected to the yoke produce lift loads. A $14000-\mathrm{kPa}$ (2000-psig) nitrogen gas system powers the cylinders. Pressure regulators connected to the nitrogen supply of each of the load cylinders adjust the magnitude of lift. Note that in the OH-58D design, the transmission at no-load is misaligned with respect to the input shaft. At $18310 \mathrm{~N}$ (4120 lb) mast lift load, the elastomeric corner mounts of the $\mathrm{OH}-58 \mathrm{D}$ transmission housing deflect such that the transmission is properly aligned with the input shaft. (In the actual helicopter, this design serves to isolate the airframe from the rotor vibration.)

The test transmission input and output shafts have speed sensors, torquemeters, and slip rings. Both load cylinders on the mast yoke are mounted to load cells. The 149-kW (200-hp) motor has a speed sensor and a torquemeter. The magnetic particle clutch has speed sensors on the input and output shafts and thermocouples. An external oil-water heat exchanger cools the test transmission oil. A facility oil-pumping and cooling system lubricates the differential, closing-end, speed increaser, and bevel gearboxes. The facility gearboxes have accelerometers, thermocouples, and chip detectors for health and condition monitoring.

\section{Test Procedure}

Two sets of the baseline design, two sets of the high-strength design, and one set of the low-noise design were manufactured and tested. Noise and vibration tests were performed on all sets of each design. One set of the baseline design and one set of the high-strength design was instrumented with strain gages and strain tests were performed on these gears. A description of the instrumentation, test procedure, and data reduction procedure is as follows:

\section{Noise Tests}

Acoustic intensity measurements were performed using the two-microphone technique. The microphones used had a flat response $( \pm 2 \mathrm{~dB})$ up to $5000 \mathrm{~Hz}$ and a nominal sensitivity of $50 \mathrm{mV} / \mathrm{Pa}$. The microphones were connected to a spectrum analyzer which computed the acoustic intensity from the imaginary part of the crosspower spectrum. Near the input region of the $\mathrm{OH}-58 \mathrm{D}$ transmission, a grid was installed which divided the region into 16 areas (Fig. 5). For each test, the acoustic intensity was measured at the center of each of the 16 areas. Only positive acoustic intensities (noise flowing out of the areas) were considered. The acoustic intensities were then added together and multiplied by the total area of the grids to obtain sound power of the transmission input region.

At the start of each test, the test transmission oil was heated using an external heater and pumping system. For all the tests, the oil used conformed to a DOD-L-85734 specification. Once the oil was heated, the transmission input speed was increased to $3000 \mathrm{rpm}$, 
a nominal amount of torque was applied, and mast lift load was applied to align the input shaft (18 $310 \mathrm{~N}$, $4120 \mathrm{lb}$ ). The transmission input speed and torque were then increased to the desired conditions. The tests were performed at 100-percent transmission input speed $(6016 \mathrm{rpm})$ and torques of 50, 75, 100, and 125-percent of maximum design. The transmission oil inlet temperature was set at $99^{\circ} \mathrm{C}\left(210^{\circ} \mathrm{F}\right)$. After the transmission oil outlet stabilized (which usually required about $20 \mathrm{~min}$ ), the acoustic intensity measurements were taken. The time to obtain the acoustic intensity measurements of the 16 grid points was about $30 \mathrm{~min}$. For each acoustic intensity spectrum at a grid point, 100 frequency-domain averages were taken. This data was collected by a computer. The computer also computed the sound power spectrum of the grids after all the measurements were taken.

\section{Vibration Tests}

Ten piezoelectric accelerometers were mounted at various locations on the $\mathrm{OH}-58 \mathrm{D}$ transmission housing (Fig. 6). The accelerometers were located near the input spiral-bevel area (accelerometers 1, 2, and 10, measuring radially to the input shaft), the ring gear area $(3,4$, and 9 , measuring radially to the planetary), and on the top cover ( 5 to 8 , measuring vertically). Accelerometers 1 to $8 \mathrm{had} \mathrm{a} 1$ to $25000-\mathrm{Hz}( \pm 3 \mathrm{~dB}$ ) response, $4 \mathrm{mV} / \mathrm{g}$ sensitivity, and integral electronics. Accelerometers 9 and 10 had a 2 to $6000-\mathrm{Hz}$ ( \pm 5 percent) response and required charge amplifiers.

The vibration tests were performed in conjunction with the noise tests. After collecting the acoustic intensity data for a given test, the vibration data was recorded on tape and processed off-line. The vibration data was later analyzed using time averaging (Fig. 7). Here, the vibration data recorded on tape was input to a signal analyzer along with a tach pulse from the transmission input shaft. The signal analyzer was triggered from the tach pulse to read the vibration data when the transmission input shaft was at the same position. The vibration signal was then averaged in the time domain using 100 averages. This technique removed all the vibration which was not synchronous to the input shaft. Before averaging, the major tones in the vibration spectrum of the $\mathrm{OH}-58 \mathrm{D}$ baseline design were the spiral-bevel and planetary gear fundamental frequencies and harmonics. Time averaging removed the planetary contribution, leaving the spiral-bevel contribution for comparing the different design configurations.

\section{Strain Tests}

Twenty strain gages were mounted on the spiralbevel pinions and 26 gages were mounted on the spiralbevel gears of one set each of the baseline and highstrength designs (Figs. 8 and 9). Gages were positioned evenly across the tooth face widths with some in the fillet area and some in the root area of the teeth. The fillet gages were placed on the drive side of the teeth. The fillet gages were also positioned at a point on the tooth cross-section where a line at a $45^{\circ}$ angle with respect to the tooth centerline intersects the tooth profile (Fig. 8(b)). The fillet gages were placed there to measure maximum tooth bending stress. Previous studies on spur gears showed that the maximum stresses were at a line $30^{\circ}$ to the tooth centerline (Hirt, 1976). $45^{\circ}$ was chosen for the current tests to minimize the possibility of the gages being destroyed due to tooth contact. In addition to maximum tensile stresses, root stresses can become significant in lightweight, thin-rimmed aerospace gear applications (Drago, 1990). Thus, root gages were centered between teeth in the root to measure gear rim stress. Tooth fillet and root gages were placed on successive teeth to determine loading consistency. The grid length of the gages was $0.381 \mathrm{~mm}$ ( $0.015 \mathrm{in.}$ ) and the nominal resistance was $120 \Omega$. The gages were connected to conditioners using a Wheatstone bridge circuitry and using a quarter-bridge arrangement.

Static strain tests were performed on both the spiral-bevel pinions and gears. A crank was installed on the transmission input shaft to manually rotate the shaft to the desired position (Fig. 10). A sensor was installed on the transmission output shaft to measure shaft position. At the start of a test, the transmission was completely unloaded and the strain gage conditioners were zeroed. Conditioner spans were then determined using shunt calibrations. The transmission was loaded (using the facility closed-loop system) to the desired torque, the shaft was positioned, and the strain readings were obtained using a computer. This was done for a variety of positions to get strain as a function of shaft position for the different gages. At the end of a test, the transmission was again completely unloaded and the conditioner zeroes were checked for drift. All static tests were performed at room temperature.

Dynamic strain tests were performed only on the spiral-bevel pinions. The pinion gages were connected to slip rings mounted on the input shaft. A slip ring assembly for the spiral-bevel gear was unavailable, and thus, dynamic strain tests of the gear were not performed. The 
test procedure was basically the same as the noise and vibration tests, except that the transmission was not run as long in order to maximize strain gage life.

\section{$\underline{\text { Results and Discussion }}$}

\section{Noise Tests}

The noise spectrum (sound power versus frequency) at 100-percent torque is given in Fig. 11. The results shown are for set 1 of the baseline configuration and set 1 of the low-noise configuration. Among the dominant spikes in the spectrum for the baseline design are the spiral-bevel meshing frequency $(1905 \mathrm{~Hz})$ and second harmonic $(3810 \mathrm{~Hz})$. Note that these tones are significantly reduced for the low-noise design. Other dominant tones in the spectrum are at the planetary meshing frequencies (fundamental at $652 \mathrm{~Hz}$ ). The planetary tones were not affected by the low-noise design. Tones from the facility closing-end gearbox (Fig. 4) were also dominant in the spectrum (fundamental at $790 \mathrm{~Hz}$ ) and as expected were not affected by the low-noise design.

The effect of torque on sound power at the spiralbevel frequencies is given in Fig. 12. Both sets of the baseline and high-strength designs and one set of the low-noise design are included. The sound power is the cumulation of the spiral-bevel meshing frequency $(1905 \mathrm{~Hz})$ and second harmonic $(3810 \mathrm{~Hz})$. The baseline and high-strength designs produced basically the same noise since the difference between them was in the tooth fillet geometry. There was some scatter in the baseline and high-strength results due to manufacturing tolerances of the different sets and assembly tolerances. To check assembly tolerances, the low-noise tests were repeated two times. Here, the gears were completed disassembled and reassembled in the transmission, and the tests were repeated. The results showed the same trend and were repeatable to within about $2 \mathrm{~dB}$. The general trend was a significant decrease in spiral-bevel gear noise for the low-noise design compared to the baseline and high-strength design. At 100-percent torque, the noise due to the spiral-bevel mesh was 12 to $19 \mathrm{~dB}$ lower than that of the baseline and high-strength designs. Also, a decrease in noise was most prevalent at 100 and 125-percent torque and less prevalent at 50 and 75-percent torque.

\section{Vibration Results}

The vibration spectrum (time-averaged acceleration versus frequency) for accelerometer 1 (input spiral-bevel housing) at 100-percent torque is given in Fig. 13. As with Fig. 11, the results compare set 1 of the baseline to set 1 of the low-noise configuration. The figure clearly shows the dominant spikes for the baseline design at the spiral-bevel meshing frequencies, and the significant reduction in spiral-bevel gear vibration for the low-noise design. The results of the other nine accelerometers were similar.

The effect of torque on vibration for accelerometers 1 and 5 is given in Fig. 14. Shown in the figure is timeaveraged acceleration processed up to $10000 \mathrm{~Hz}$. The results are root-mean-square (rms) calculations of the time-domain signals. Since the time-averaging removed vibration nonsynchronous to the input shaft, the results in Fig. 14 were basically the cumulation of the spiralbevel meshing frequency $(1905 \mathrm{~Hz})$ and second through fifth harmonics.

As with the noise measurements, the vibration for the baseline and high-strength designs were similar but with scatter. Again, the figure clearly shows a significant reduction in spiral-bevel gear vibration for the low-noise design compared to the baseline and high-strength designs. Like the noise results, the reduction in vibration for the low-noise design was greater at the higher torques (100 and 125 percent). The results of the other eight accelerometers were similar. From the results of all 10 accelerometers and at 100-percent torque, the vibration for the low-noise design due to the spiral-bevel mesh was on the average 5 to $10 \mathrm{~g}$ 's lower than that of the baseline and high-strength designs.

\section{$\underline{\text { Strain Tests }}$}

Figure 15 shows the results of a typical static strain test of the spiral-bevel pinion. A uniaxial stress field was assumed to exist at the strain gage and the stress was determined by multiplying the measured strain by Young's modulus for steel. For a pinion fillet gage, the stress was first compressive, then tensile. Since the pinion drove the gear, the compression occurred when the tooth in mesh prior to the strain-gaged tooth was loaded, causing compression in the gage. As the pinion rotated, the strain-gaged tooth was loaded in single-tooth contact and the gage measured the maximum tensile stress. Similar conditions existed for the pinion root gage except the gage measured the stress of the pinion rim rather than tooth bending. The results for the spiral-bevel gear were similar to the pinion except the tensile stress occurred before the compression since the pinion drove the gear.

Figure 16 shows the distribution of maximum tensile and compressive stress during contact along the tooth face width for the baseline and high-strength designs. The most important item to note is the reduction in maximum tensile bending stress of the high-strength design compared to the baseline design. The maximum 
tensile stress of the high-strength design was reduced on the average 27 percent compared to the baseline for the spiral-bevel pinion (Fig. 16(a)). There was, however, an increase in the maximum compressive fillet stress for the spiral-bevel pinion. Thus, the alternating stress of the high-strength design was reduced on the average 14 percent compared to the baseline (the alternating stress is defined as the maximum tensile stress plus the absolute value of the maximum compressive stress). For the spiral-bevel gear, the maximum tensile stress of the high-strength design was reduced on the average 10 percent compared to the baseline and the alternate was reduced on the average 12 percent (Fig. 16(c)). Thus, the increase in fillet radii of the high-strength design has a significant benefit in increasing the tooth bending capacity of the gear tooth.

There was a significant increase in the maximum compressive root stress of the high-strength design compared to the baseline spiral-bevel pinion (Fig. 16(b)) and a slight increase for the gear (Fig. 16(d)). This was probably due to the removal of material for the increased fillet, thus lowering the rim thickness. For the $\mathrm{OH}-58 \mathrm{D}$ design, this increase in stress is acceptable, but in general, these effects need to be considered in a design.

Figure 16 also shows the results of the dynamic strain tests for the spiral-bevel pinion. The results of the dynamic strain tests matched closely to those of the static. The stress-position plots were similar as well as the maximum and minimum stresses, indicating no detrimental dynamic effects.

\section{Summary of Results}

Advanced-design spiral-bevel gears were tested in an $\mathrm{OH}-58 \mathrm{D}$ helicopter transmission using the NASA 500-hp Helicopter Transmission Test Stand. Three different gear designs were tested. The baseline design was the current design of the $\mathrm{OH}-58 \mathrm{D}$ transmission, except the gear material was X-53 rather than AISI 9310. The second design was a higher-strength design which was the same as the baseline but incorporated a full fillet radius to reduce gear tooth bending stress. The third design was a lower-noise design which was the same as the high-strength design except the tooth geometry was modified to reduce transmission error and noise. Noise, vibration, and tooth strain tests were performed. The following results were obtained:

1. For the baseline spiral-bevel gear design, dominant tones in the noise and vibration spectra occurred at the spiral-bevel meshing frequencies and harmonics. A significant decrease in the spiral-bevel tones resulted from the low-noise design. At 100-percent torque, the noise (sound power) due to the spiral-bevel meshing frequencies of the low-noise design was 12 to $19 \mathrm{~dB}$ lower than that of the baseline and high-strength designs. Using a time-average processing scheme, the spiral-bevel gear vibration of the low-noise design was 5 to $10 \mathrm{~g}$ 's lower than that of the baseline and high-strength designs.

2. The increased fillet radius of the high-strength design had a significant benefit in decreasing tooth bending stress. For tests at 100-percent torque, the spiral-bevel pinion maximum tooth bending stress of the high-strength design was on the average 27-percent lower than that of the baseline design. There was, however, an increase in the maximum compressive stress at the center of the tooth root.

\section{$\underline{\text { References }}$}

Bill, R.C., "Advanced Rotorcraft Transmission Program," NASA TM-103276, 1990.

Drago, R.J., "Design Guidelines for High-Capacity Bevel Gear Systems," AE-15 Gear Design, Manufacturing and Inspection Manual, Society of Automotive Engineers, Warrendale, PA, 1990, pp. 105-121.

Fong, Z.H., and Tsay, C.B., "Kinematic Optimization of Spiral Bevel Gears", Journal of Mechanical Design, Vol. 114, No. 3, Sept. 1992, pp. 498-506.

Gosselin, C., Cloutier, L., and Brousseau, J., "Tooth Contact Analysis of High Conformity Spiral Bevel Gears," Proceedings of the International Conference on Motion and Power Transmissions, Nov. 23-26, 1991, Hiroshima, Japan.

Henry, Z.S., "Advanced Rotorcraft Transmission (ART) -Component Test Results," Presented at the 28th AIAA/ASME/SAE Joint Propulsion Conference, Nashville, TN, July 6-8, 1992.

Henry, Z.S., "Preliminary Design and Analysis of an Advanced Rotorcraft Transmission," AIAA/ ASME/SAE/ASEE 27th Joint Propulsion Conference, Proceedings, AIAA, Washington, DC, 14 p., 1991.

Hirt, M.C.O., "Stress in Spur Gear Teeth and Their Strength as Influenced by Fillet Radius," Dissertation, American Gear Manufacturers Association, Ph.D. Thesis, 1976.

Scott, H.W., "Computer Numerical Control Grinding of Spiral Bevel Gears," NASA CR-187175, 1991.

Lewicki, D.G., and Coy, J.J., "Vibration Characteristics of OH-58A Helicopter Main Rotor Transmission," NASA TP-2705, 1987.

Litvin, F.L., and Zhang, Y., "Local Synthesis and Tooth Contact Analysis of Face-Milled Spiral Bevel Gears," NASA CR-4342, 1991. 
Litvin, F.L., Zhang, Y., and Chen, J., 'User's Manual for Tooth Contact Analysis of Face-Milled Spiral Bevel Gears With Given Machine-Tool Settings," NASA CR-189093, 1991.

Litvin, F.L., Kuan, C., and Zhang, Y., "Determination of Real Machine-Tool Settings and Minimization of Real Surface Deviation by Computer Inspection," NASA CR-4383, 1991.

Mitchell, A.M., Oswald, F.B., and Coe, H.H., "Testing of UH-60A Helicopter Transmission in NASALewis 2240-kW (3000-hp) Facility," NASA TP-2626, 1986.

Vialle, M., "Tiger MGB-, High Reliability-, Low Weight," Proceedings of the 47th American Helicopter Society Annual Forum Proceedings, Vol. 2, AHS, Alexandria, VA, 1991, pp. 1249-1258.
TABLE I.-BASELINE SPIRAL-BEVEL GEAR DESIGN

PARAMETERS OF THE OH-58D MAIN-ROTOR

TRANSMISSION

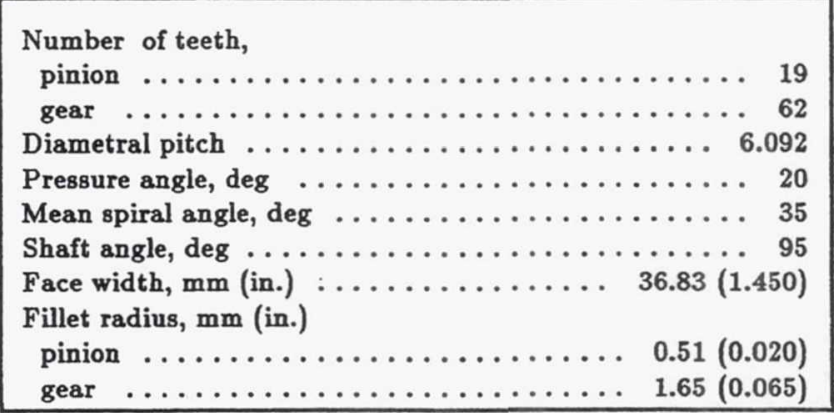

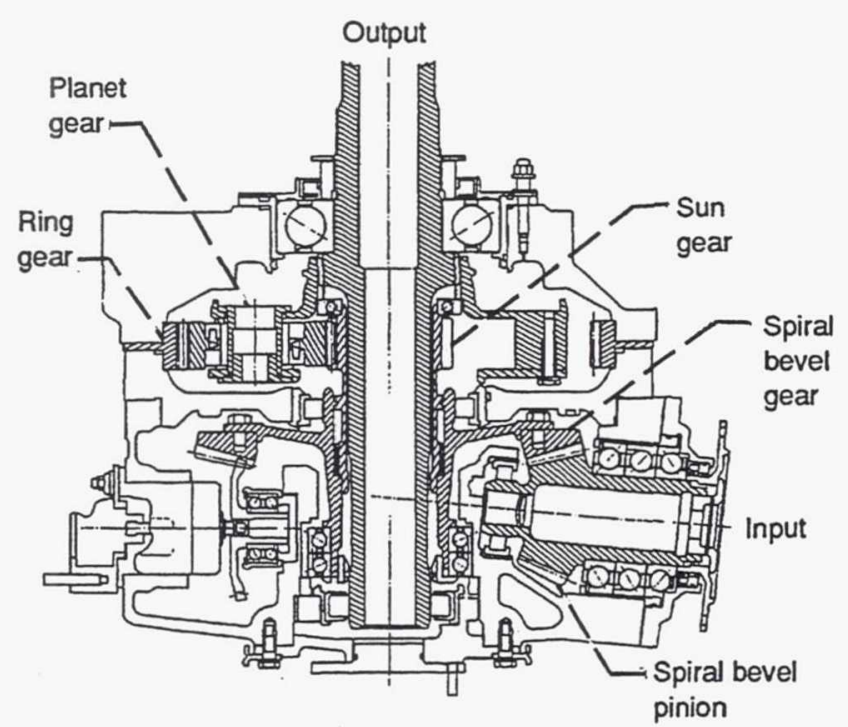

Figure 1.- $\mathrm{OH}-58 \mathrm{D}$ helicopter main-rotor transmission.

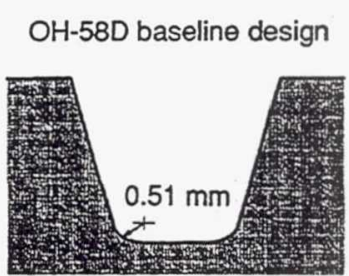

High-strength design

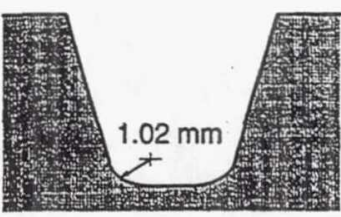

a) Pinion.
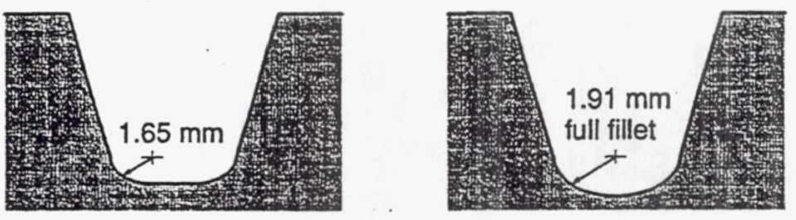

b) Gear.

Figure 2.-Comparison of $\mathrm{OH}-58 \mathrm{D}$ and high-strength spiralbevel gear designs. 


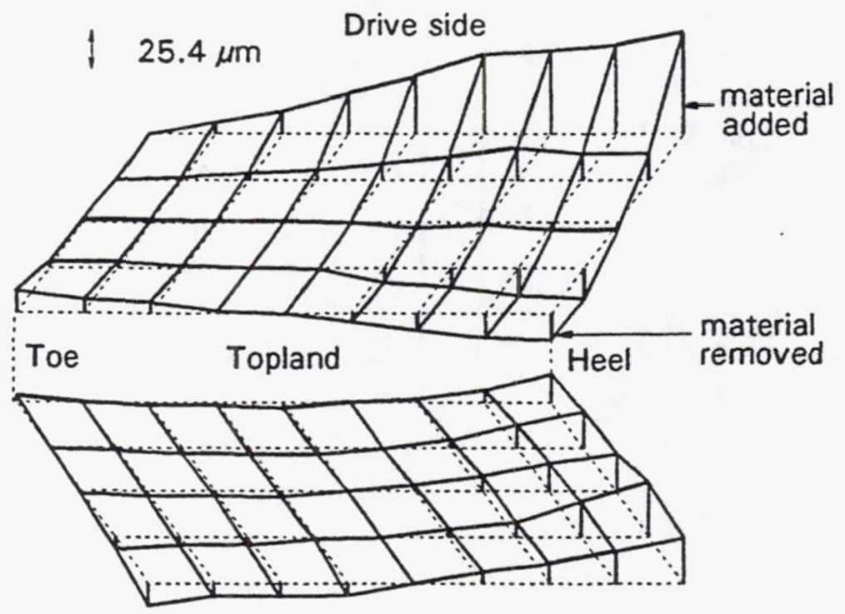

Coast side

Figure 3.-Topological comparison of OH-58D and low-noise spiral-bevel pinion.

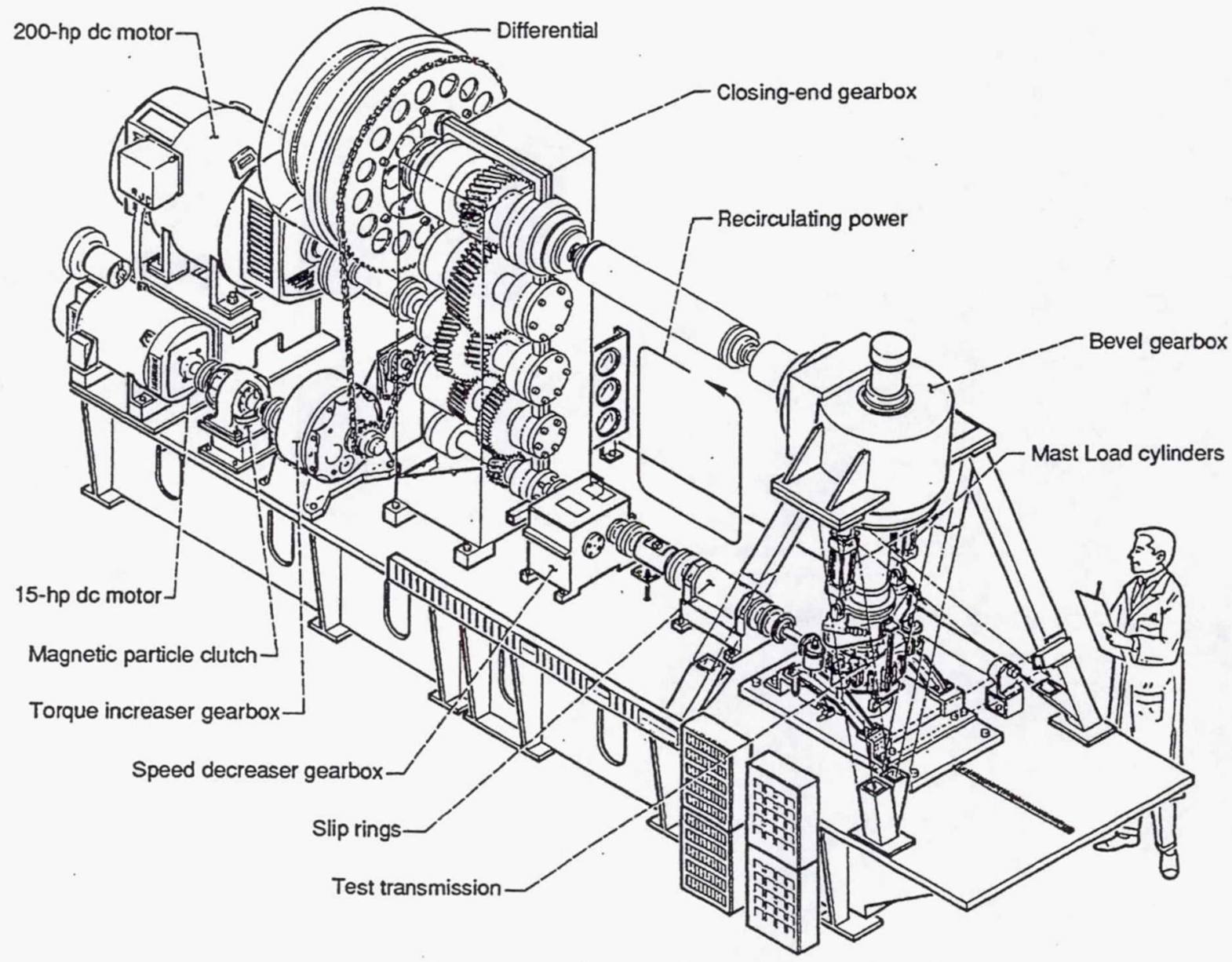

Figure 4.-NASA Lewis 500-hp helicopter transmission test stand. 


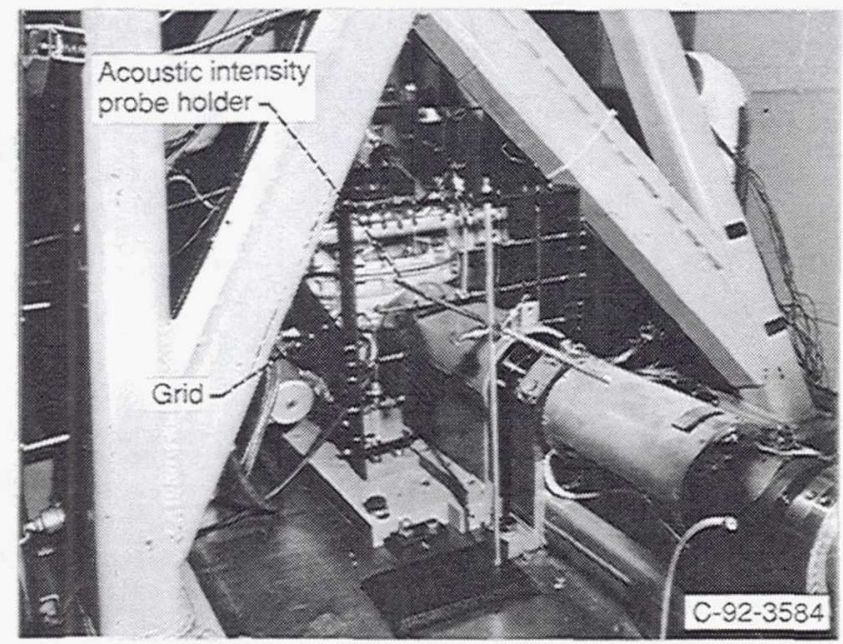

Figure 5.-Grid for sound intensity measurements.

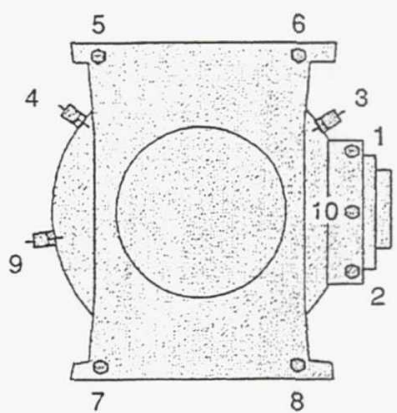

a) Top view.

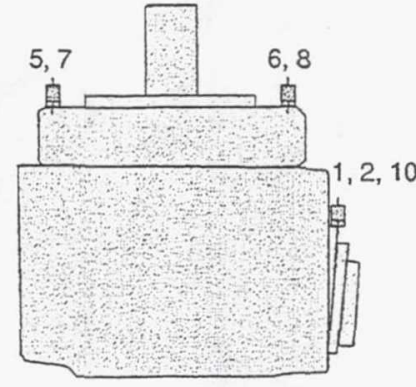

b) Side view.

Figure 6.-Accelerometer locations on $\mathrm{OH}-58 \mathrm{D}$ transmission.

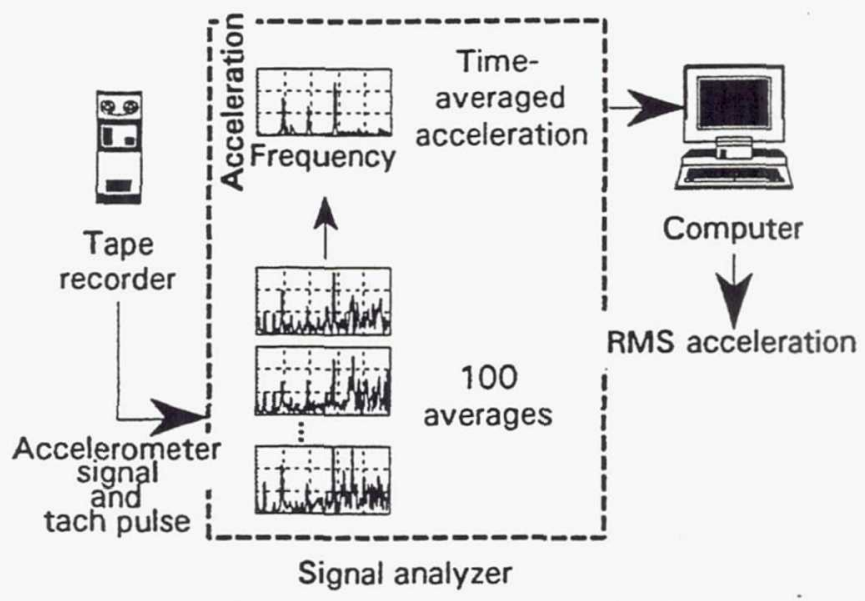

Figure 7.-Data reduction scheme of vibration tests. 


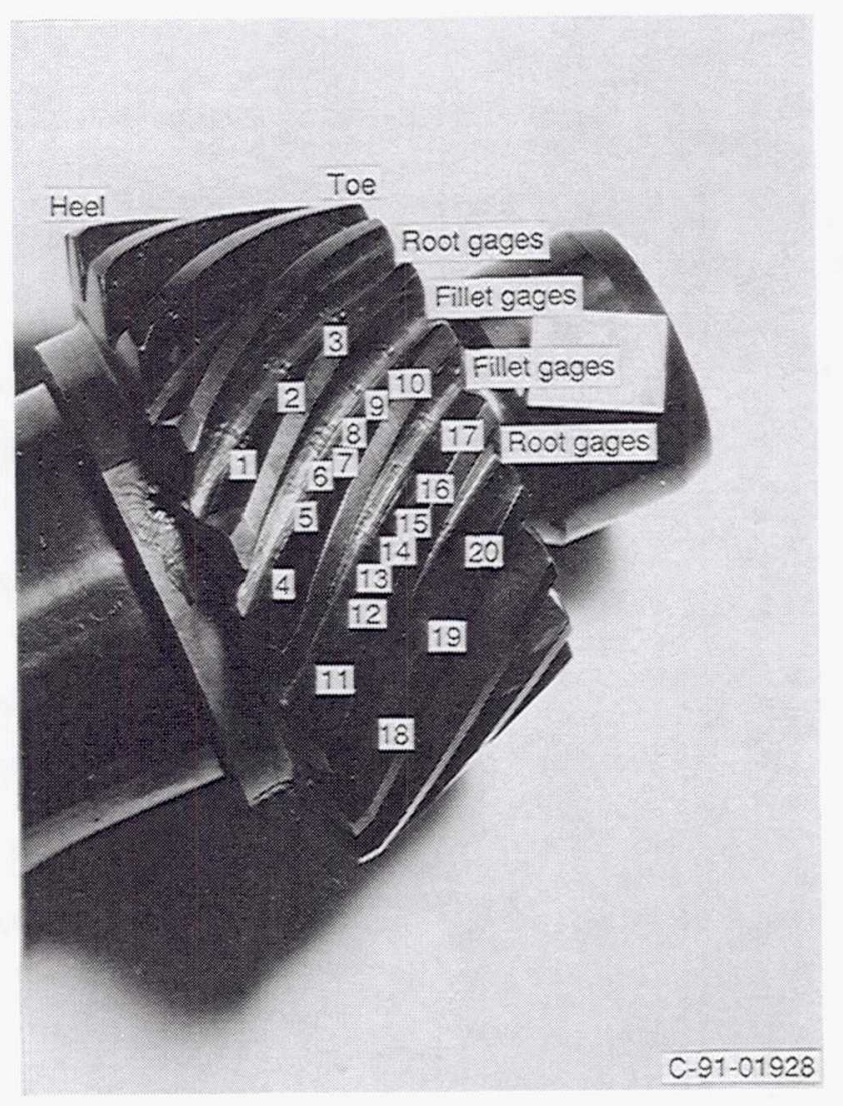

a) Gage numbering.

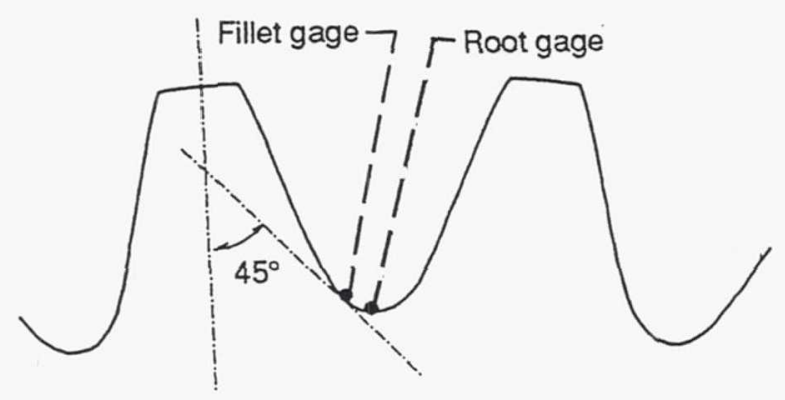

b) Cross-sectional view.

Figure 8.-Strain gage locations on spiral-bevel pinion.

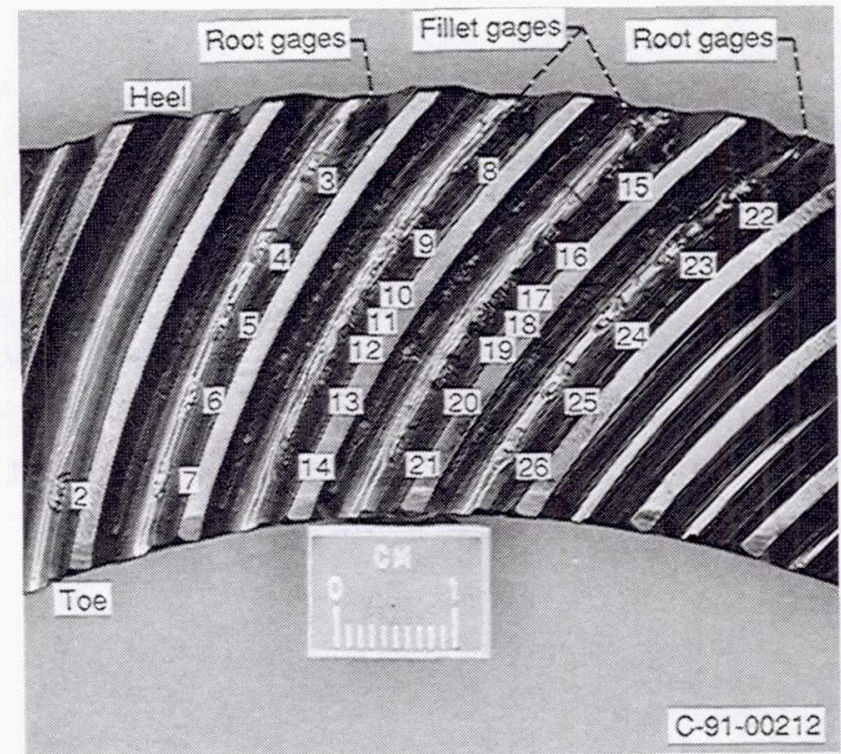

Figure 9.-Strain gage locations on spiral-bevel gear.

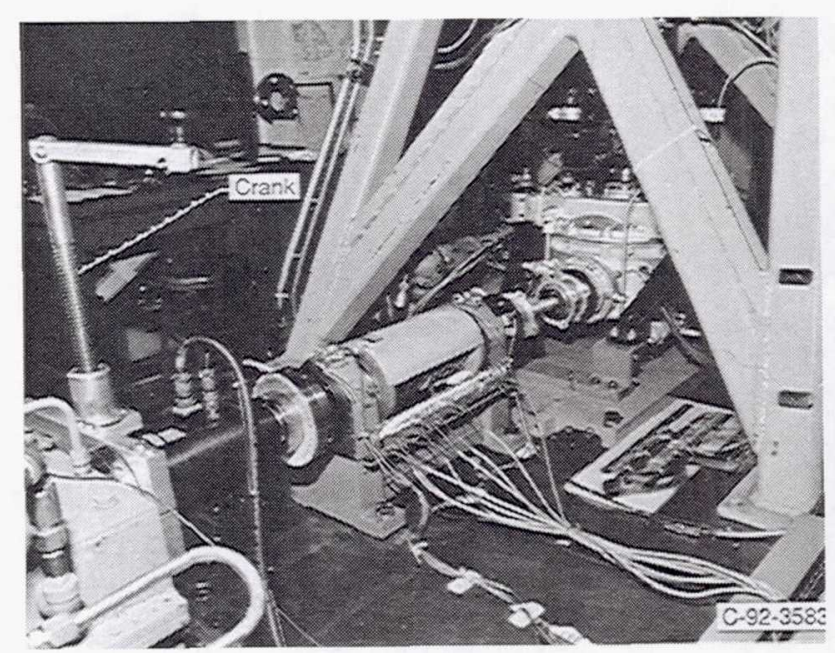

Figure 10.- Setup for static stress tests. 


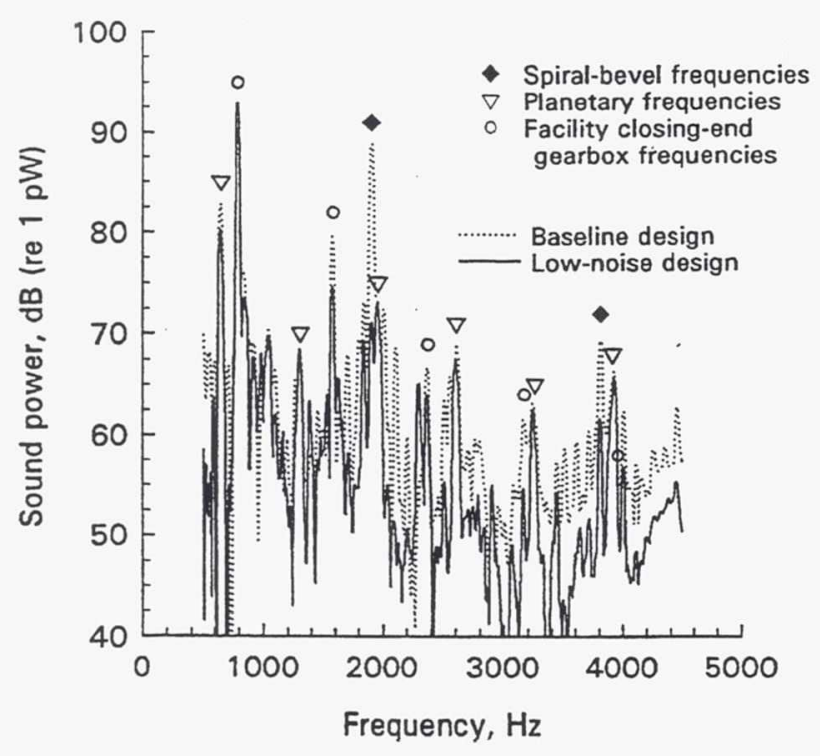

Figure 11.-Noise spectrum; test at 100-percent torque.

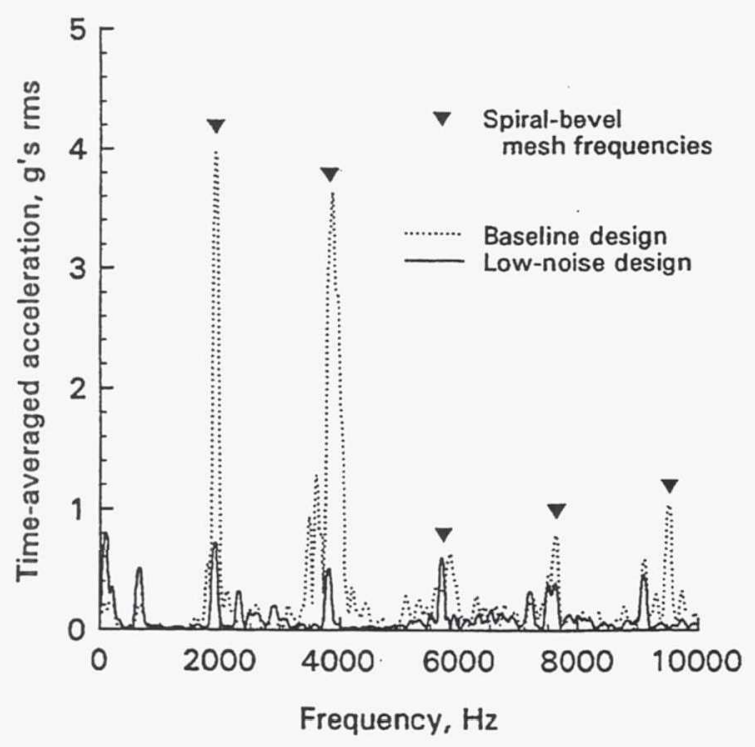

Figure 13.-Vibration spectrum; accelerometer 1, test at 100-percent torque.

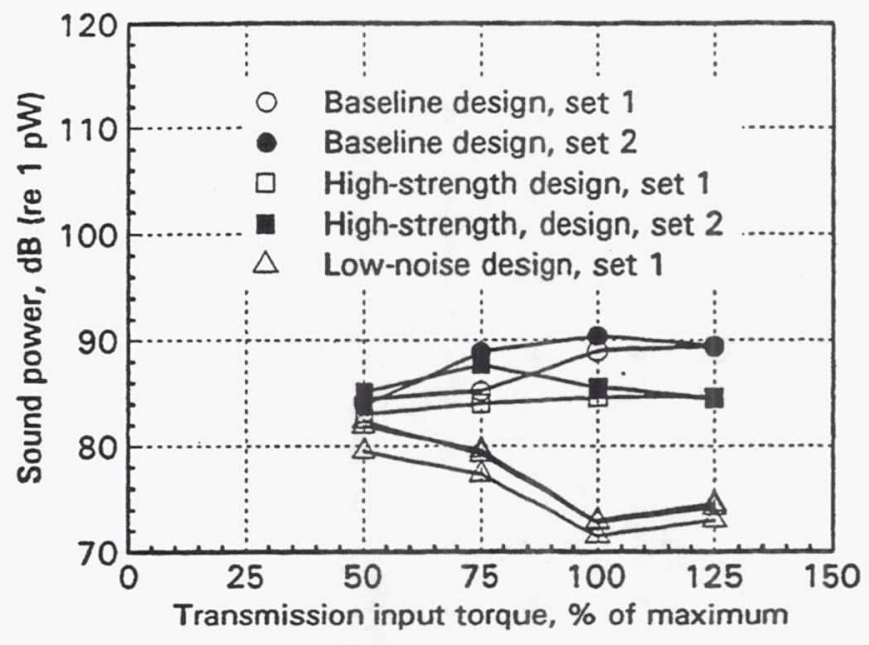

Figure 12.-Noise test results; sound power at spiral-bevel mesh frequencies (first two harmonics) versus transmission input torque.

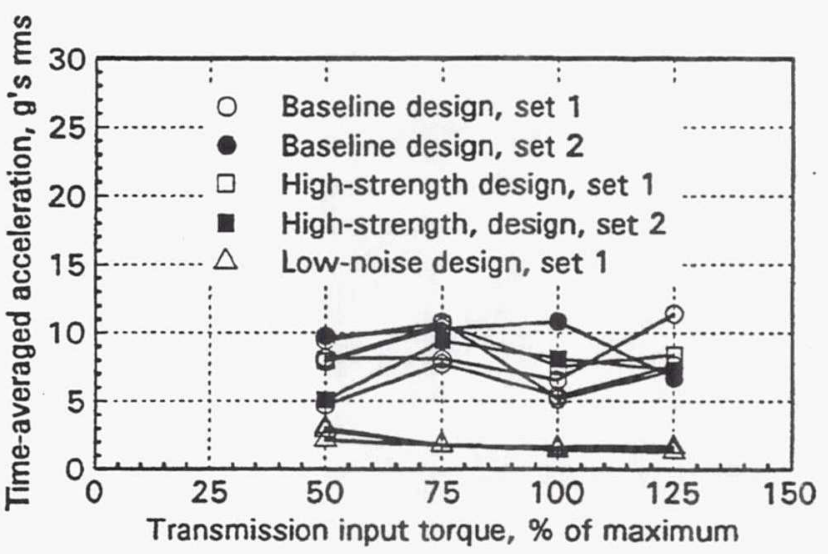

a) Accelerometer 1, input spiral-bevel housing.

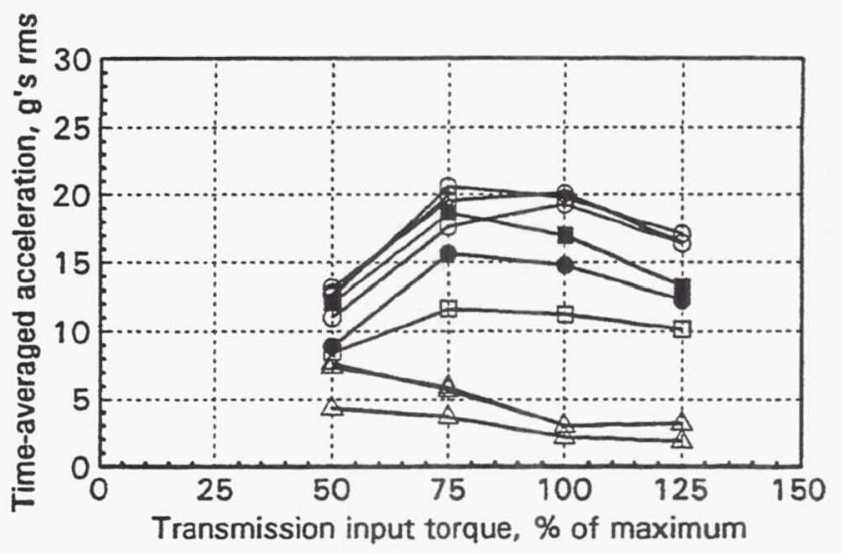

b) Accelerometer 5, top housing.

Figure 14.-Typical vibration test results. 


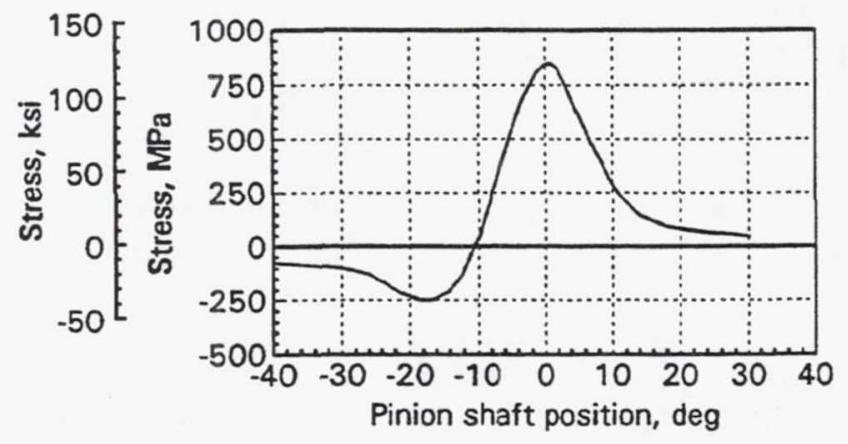

a) Fillet gage 14 .

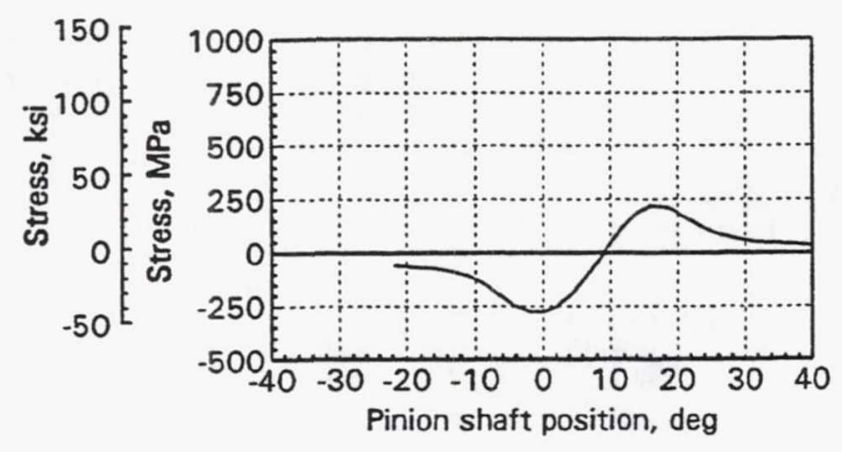

b) Root gage 2 .

Figure 15.-Typical strain test results; spiral-bevel pinion, 100-percent torque. 
- Baseline desigr, static tests

- Baseline design, dynamic tests

- High-strength design, static tests

- High-strength, design, dynamic tests

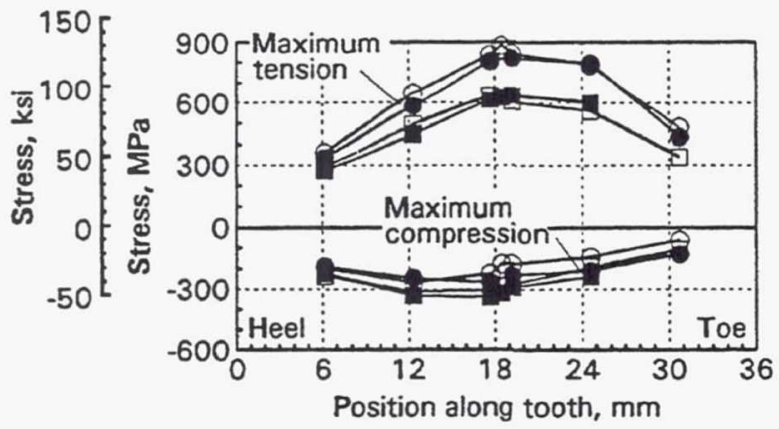

a) Spiral-bevel pinion fillet gages.

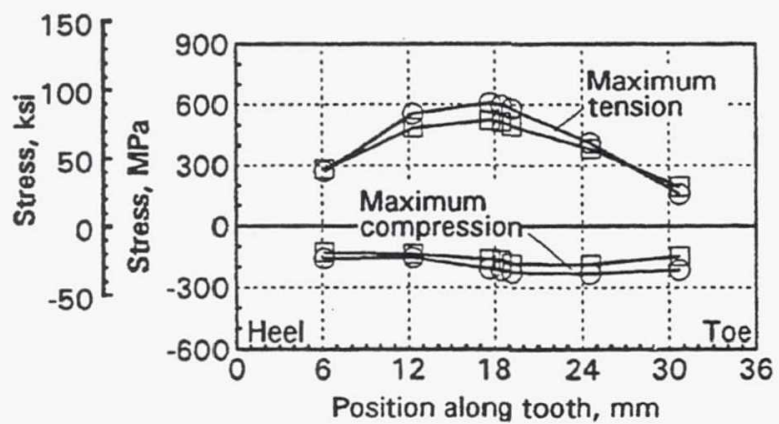

c) Spiral-bevel gear fillet gages.

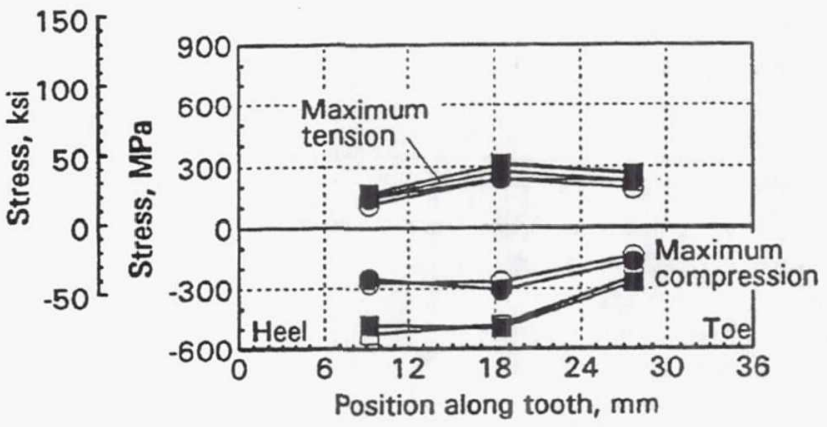

b) Spiral-bevel pinion root gages.

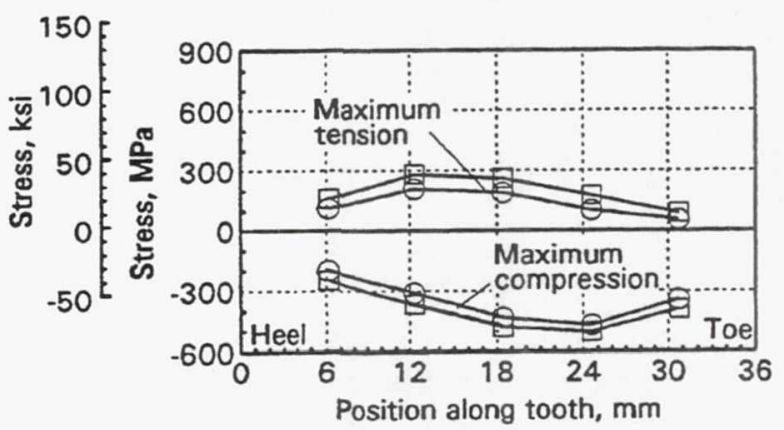

d) Spiral-bevel gear root gages.

Figure 16. -Strain test results; 100 -percent torque. 
Public reporting burden for this collection of information is estimated to average 1 hour per response, including the time for reviewing instructions, searching existing data sources, gathering and maintaining the data needed, and completing and reviewing the collection of information. Send comments regarding this burden estimate or any other aspect of this Davis Highway, Suite 1204, Arlington, VA 22202-4302, and to the Office of Management and Budget, Paperwork Reduction Project (0704-0188), Washington, DC 20503.

\begin{tabular}{|l|c|r|}
\hline 1. AGENCY USE ONLY (Leave blank) & $\begin{array}{c}\text { 2. REPORT DATE } \\
\text { June } 1993\end{array}$ & $\begin{array}{l}\text { 3. REPORT TYPE AND DATES COVERED } \\
\text { Technical Memorandum }\end{array}$ \\
\hline
\end{tabular}

\section{TITLE AND SUBTITLE}

Low-Noise, High-Strength, Spiral-Bevel Gears for Helicopter Transmissions

\section{AUTHOR(S)}

David G. Lewicki, Robert F. Handschuh, Zachary S. Henry, and Faydor L. Litvin
5. FUNDING NUMBERS

\section{PERFORMING ORGANIZATION NAME(S) AND ADDRESS(ES)}

NASA Lewis Research Center

Cleveland, Ohio 44135-3191

and

Vehicle Propulsion Directorate

U.S. Army Research Laboratory

Cleveland, Ohio 44135-3191

9. SPONSORING/MONITORING AGENCY NAMES(S) AND ADDRESS(ES)

National Aeronautics and Space Administration

Washington, D.C. 20546-0001

and

U.S. Army Research Laboratory

Adelphi, Maryland 20783-1145
WU-505-62-10

1L162211A47A

\section{SUPPLEMENTARY NOTES}

Prepared for the 29th Joint Propulsion Conference and Exhibit cosponsored by the AIAA, SAE, ASME, and ASEE, Monterey, California, June 28-30, 1993. David G. Lewicki and Robert F. Handschuh, Vehicle Propulsion Directorate, U.S. Army Research Laboratory, Lewis Research Center. Zachary S. Henry, Bell Helicopter Textron, Inc., Fort Worth, Texas 76101. Faydor L. Litvin, University of Illinois at Chicago, Chicago, Illinois 60680. Responsible person, David G. Lewicki, (216) 433-3970.

12a. DISTRIBUTION/AVAILABILITY STATEMENT

12b. DISTRIBUTION CODE

Unclassified - Unlimited

Subject Category 37

NASA TM-106080

AIAA-93-2149

ARL-MR-71

8. PERFORMING ORGANIZATION REPORT NUMBER

E-7698

D. SPONSORING/MONITORING AGENCY REPORT NUMBER 